\title{
Delivering the AAMC “Teaching for Quality” Program through a Community-Based GME Collaborative: Lessons Learned to Date
}

\author{
Brandy Church, MA¹, William Corser, PhD, RN¹, Jonathan Rohrer, PhD, DMin ${ }^{1}$, Kari Hortos, DO ${ }^{1}$, Angela Harrison \\ 1 Statewide Campus System, College of Osteopathic Medicine Michigan State University, East Lansing, MI \\ Keywords: scholarly activity, quality improvement, patient safety, graduate medical education \\ https://doi.org/10.51894/001c.6977
}

\section{Spartan Medical Research Journal}

Vol. 3, Issue 2, 2018

\begin{abstract}
CONTEXT
To address scholarly activity (SA) accreditation standards, the Michigan State University's College of Osteopathic Medicine Statewide Campus System has offered the Association of American Medical Colleges' (AAMC) Teaching for Quality Program for two cohorts of community-based faculty. The purpose of this paper was to describe the design and delivery of the customized program, the authors' initial lessons learned, and their plans for further evaluation and dissemination.
\end{abstract}

\section{METHODS}

The authors customized the program to overcome the barriers typically faced by community-based program faculty learners through a graduate medical education (GME) consortium model. This was the first time this program was delivered in this manner

\section{RESULTS}

The authors' initial cohort of 19 learners successfully developed 15 projects, with two pairs of learners collaborating on projects. The second cohort of 15 learners developed 11 projects, with one pair of learners collaborating. The authors present a series of principles for community-based GME leaders striving to develop SA projects in their respective GME environments.

\section{CONCLUSIONS}

The "consortium advantage" derived from entities such as the SCS may prove integral to efficiently coordinating SA project resources and knowledge across diverse GME systems.

\section{INTRODUCTION}

During recent years, graduate medical education (GME) in the U.S. has continued to experience substantial changes, most notably moving to a single accreditation system. Under this new system, graduates of both allopathic and osteopathic medical schools complete residency and/or fellowship training in programs accredited by the Accreditation Council for Graduate Medical Education (ACGME). ${ }^{1}$ All resident physicians and GME faculty are required to meet common standards and requirements as outlined in the ACMGE's Next Accreditation System (NAS). ${ }^{1,2}$

Many community-based residency programs have experienced considerable challenges meeting these new ACGME requirements, particularly those related to increased faculty and residents scholarly activity (SA) project expectations and compliance with the Clinical Learning Environment Review (CLER). ${ }^{3-6}$ Community-based GME officials may be especially challenged meeting accreditation standards due to barriers including: 1) lack of time, 2) inadequate training and experience, and 3) lack of resources and knowledge required to complete SA projects and disseminate results. ${ }^{7-12}$
To address SA accreditation standards, the Statewide Campus System (SCS) at Michigan State University's College of Osteopathic Medicine (MSUCOM) ${ }^{13}$ has offered the Association of American Medical Colleges' (AAMC) Teaching for Quality (Te4Q) Program for two cohorts of community-based faculty. ${ }^{14}$ SCS customized the program to overcome the barriers typically faced by community-based program faculty by training cohorts of learners through a consortium model. This was the first time this program had been delivered in this manner.

The purpose of this paper is to describe the design and delivery of the program, the authors' initial lessons learned, and their plans for further evaluation and dissemination. The authors will conclude with a series of general principles for GME leaders striving to develop projects at their respective SA environments.

\section{METHODS}

\section{SETTING}

The SCS was founded in 1989 as a statewide consortium to 
improve the quality of Michigan osteopathic GME. ${ }^{13}$ Today, the SCS represents 37 community-based hospitals, 7 federally qualified health centers, and 176 residency programs accredited by the ACGME and/or the American Osteopathic Association (AOA). The consortium is charged with serving the GME needs of residency designated institutional officers, directors of medical education, program directors and over 1,900 residents and fellows.

\section{PROGRAM PLANNING}

The $\mathrm{Te} 4 \mathrm{Q}^{14}$ program is a multi-faceted faculty development program designed to train faculty learners to teach effective quality improvement and patient safety (QIPS) principles to medical students, residents, and other clinicians. The AAMC initially (2013) designed the program to train up to 30 faculty in a single institution over a 15-to-18 month timeframe to:

- Identify a gap in their QIPS education;

- Design a feasible QIPS project to address that gap;

- Conduct the project and assess its impact; and

- Produce a SA poster, article, or presentation concerning their project results.

This overall training program sequence is illustrated in Figure 1.

During the original planning process, the SCS Office of Faculty Development recognized that program implementation through a consortium would present unique challenges (e.g. more complex cross-system communications, GME program variations, etc.) for both SCS "coaches" and faculty learners. Additionally, the authors recognized that the program would need to be customized to overcome the barriers typically faced by community-based clinicians conducting SA projects. Therefore, they proposed the following modifications to the delivery of the program to central AAMC office faculty who were especially supportive:

\section{BARRIER \# 1: LACK OF TIME}

Program resource identification. The authors customized the $\mathrm{Te} 4 \mathrm{Q}^{14}$ program during the following phases: preparation for participation, a 1.5-day project planning workshop, project design, implementation, results, analysis, and dissemination. Resources were then identified to help maximize learners' efficiency progressing through each SA project phase. Project completion time estimates were provided, and this information was incorporated into all promotional program materials.

Articulation of program time commitment. The SCS leadership presented to its Education Standards Committee and Governing Board a detailed timeline, complete with monthly time estimates to which learners would need to commit. As both committees were comprised of leadership from each member hospital, this step was essential to ensure that learners' institutional leaders would understand and be supportive of the commitment required for their faculty to complete the program. Program applicants were then required to complete a four-page learning contract, committing to the program time expectations.

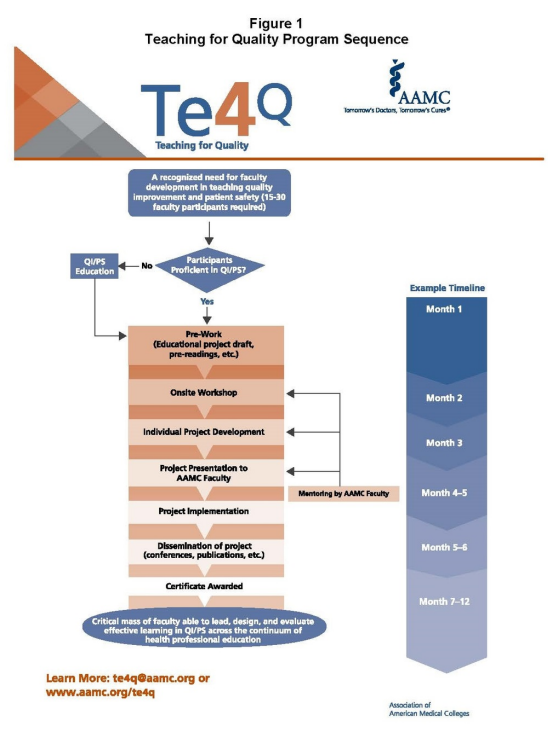

Figure 1 Teaching for Quality Program Sequence

\section{BARRIER \# 2: INADEQUATE TRAINING AND EXPERIENCE}

Common QIPS knowledge base. Acknowledging that learners would attend this program with a variety of preprogram experiences, the authors devised a plan to establish a common QIPS vocabulary for program communications. Learners were encouraged to complete two Institute for Healthcare Improvement (IHI) ${ }^{15}$ modules concerning QIPS and read an article concerning CLER ${ }^{3}$ in addition to the required pre-workshop assignments. Learners were also encouraged to watch additional IHI modules and attend the SCS-sponsored workshop to at least "brush up" on QIPS content prior to starting their SA project planning. A library of over 300 publicly-accessible project support materials (i.e. voiced-over PowerPoint modules regarding feasible project design, IRB applications, data set creation, analytic techniques, project tip sheets and templates, pertinent GME articles, etc.) files were made available and posted on the program course website.

SCS faculty coaches. The SCS Office of Faculty Development quickly recognized from learners' pre-workshop selfassessment statements that most learners had never developed a prior SA project. The authors therefore identified themselves to serve as learner coaches for different projects based on the project focus and the coach's areas of expertise.

Narrowed project focus. SCS required program learners to select one $\mathrm{CLER}^{3}$ pathway focus area from a list of fifteen that would comprise their project focus. Learners then designed a project with their coaches within that domain that was also in alignment with their individual health system's priorities. By narrowing the scope of program projects in this manner, the authors could help: 1) facilitate project 
feasibility, 2) learners utilize available SCS resources without overextending assigned coaches, and 3) create learner project clusters for possible SA project collaboration. ${ }^{16-21}$

\section{BARRIER \# 3: LACK OF INSTITUTIONAL RESOURCES}

Communication and resource accessibility. The authors worked to help ensure that learners would each have: 1) ready access to resources and materials for future projects, 2) a place to archive important project-related documents, and 3) a feasible mechanism to communicate with other learners and coaches. We therefore created an online course using Desire2Learn ${ }^{22}$ course management software.

This online course site became a repository of recent articles concerning SA in GME settings, resources related to IRB application and project design, project timeline and deadline templates, discussion boards for frequently asked questions, and drop boxes for important project documentation. The drop boxes also enabled coaches to offer ongoing guidance, consultation, and feedback based on what learners had submitted.

\section{LEARNER RECRUITMENT}

The recruitment of $\mathrm{Te} 4 \mathrm{Q}^{14}$ program applicants included promotional materials containing information about how participation would help them meet NAS and SA standards. Additional proposed reasons to apply included that: a) completed SA projects would improve GME education in QIPS and awareness of system errors; b) provide learners with SA skills for themselves and their residents; and c) result in systemic improvement in one specific CLER ${ }^{3}$ pathway. We successfully enrolled a total of 19 participants from 13 different SCS member systems in our first 2015-2016 cohort and 15 participants from 10 different SCS member systems in our second 2017-2018 cohort.

We have concluded that the overall process of promoting the program as an appealing GME investment primarily involved two simultaneous processes: a) obtaining "buy-in" from multiple system and residency program stakeholders, and $b$ ) adequately customizing the program to prove more feasible/appealing to potential community-based GME learners.

\section{PROGRAM IMPLEMENTATION}

In January 2015, applicants were notified of their program selection and provided a packet of pre-workshop assignments with completion deadlines and the contact information of their assigned coach. AAMC faculty primarily taught the workshop in March. Learners then worked with their coaches to refine their project, evaluate project feasibility, and prepare appropriate IRB applications.

A follow-up webinar occurred that August with AAMC faculty, SCS coaches, and learners to provide a 10-minute status report on their projects. At the end of the program in May of the next year, learners disseminated their SA project findings at a regional poster day to earn completion certificates from both the AAMC and MSU.

\section{RESULTS}

Our initial 2015-2016 cohort of 19 learners developed 15 projects, with two pairs of community-based faculty collaborating on two separate projects. Two learners withdrew from the program, one leaving the area for another GME position. Our second 2017-2018 cohort of 15 learners developed 11 projects, with one pair of participants opting to collaborate. Three learners withdrew from the program due to positional changes or competing GME position demands.

To date, about $50 \%$ of program projects have been specifically oriented to testing the implementation, delivery, and evaluation of QIPS curricula and content for either residents and/or faculty. The remaining projects addressed specific aspects of healthcare delivery processes such as surgical suite waiting times, postoperative patient follow-up calls, opioid prescribing patterns, cross-shift resident handoffs, timely reporting of critical patient lab results, assessing patients for severe sepsis, and implementing a series of group visits for patients with complex diabetes management needs.

Two projects involved education of residents concerning osteopathic manipulative medicine treatments. Those SA projects involving any protected patient health information were designed to have system Quality Improvement department personnel de-identify patient data to avoid HIPAA-related infringements ${ }^{23}$ and facilitate IRB approval.

\section{DISCUSSION}

We have identified the following principles for GME settings:

1. Compiling resources and streamlining project design processes can reduce learner time commitment and increase their SA project engagement.

Since community-based faculty are so often busy with patient care demands, prospective QIPS projects can be perceived as "just one more thing to be done".7,9,10,12,24 Still, our Te4Q learners generally indicated that their project planning was made more manageable by proactively planning their project schedules based on provided timeline templates. Several learners also stated that the resources SCS coaches had provided them helped them save time. Some learners placed positive comments of other posted online resources.

In hindsight, it appears that those learners who utilized available program-related resources tended to have smoother project design experiences. It was, however, also especially evident that sizable variations existed across systems (e.g. degree of QI department capability, complexity of IRB application reviews, accessibility of data-capable support personnel, potential resistance from other GME faculty) which either facilitated or impeded successful project completion. $8,17,24-27$

The SCS Office of Faculty Development also reviewed overall differences in project design needs between primary care and specialist providers, the extent to which different learners wanted to obtain (or avoid using) protected patient health data. The authors have concluded that regularly assessing such differences across learners' healthcare systems 
will be helpful for future Te4Q cohorts. Clearly, some learners preferred to be left alone after being provided a "critical mass" of project support materials, while others preferred to exchange project updates or engage in ongoing problemsolving discussions with coaches and colleagues. .11,24 $^{2}$

2. Helping learners attain a solid QIPS knowledge base may make them more confident and capable of completing SA projects

Most learners stated that the assigned pre-workshop $\mathrm{IHI}^{15}$ modules and readings enhanced their understanding of QIPS concepts and project design principles. Although the QIPS workshop has probably been effective for most learners, the actual outcomes derived from such intensive content-laden events may be less helpful for more novice learners. Since different types of SA workshop/“boot camp” approaches exist, ${ }^{20,28}$ the SCS Office of Faculty Development is currently revising the workshop curriculum for future $\mathrm{Te} 4 \mathrm{Q}$ cohorts.

3. Providing assigned coaches with compatible project-related skills can serve to keep learner SA projects moving forward.

The provision of coaches with compatible osteopathic provider, educational specialist, and project design expertise appeared to be critical for many learners during their early project planning. Similar to other settings, several program learners indicated that they appreciated most coach feedback, as well as the accountability they felt to complete project developments to provide periodic updates for their coaches. ${ }^{18,29-32}$

\section{CONCLUSIONS}

This paper summarizes the authors' experiences of delivering the AAMC Te $4 \mathrm{Q}^{14}$ program to two cohorts of community-based faculty through an established GME consortium. Since both community and university-based residency program officials are now required to meet increasingly rigorous SA standards, the principles outlined in this paper may prove generalizable to the complex SA challenges of GME officials across the nation.

It will very likely take several additional cohorts of learners for the authors to determine the sustainability of programs such as $\mathrm{Te} 4 \mathrm{Q}^{14}$ to enable diverse community-based GME leaders to: a) improve their capacity for SA projects, b) implement meaningful SA project supports, and c) incrementally refine key processes to sustain momentum gained from initial SA projects. ${ }^{23,31-33}$

Several groups have suggested that the "consortium advantage" from such entities as the SCS may prove integral to more efficiently sharing SA resources and capitalizing on project-related expertise across diverse GME settings. $18,25,30,31$ Ideally, these paper conclusions will contribute to the development of more innovative approaches for the thousands of community-based GME programs now held to SA expectations. ${ }^{34,35}$

\section{FUNDING}

The authors report no external funding source for this study.

\section{CONFLICT OF INTEREST}

The authors declare no conflict of interest.

\section{ACKNOWLEDGMENTS}

Karyn Baum, MD, MSEd, Senior Consultant, AAMC for guidance in delivering the Te4Q program and reviewing this developing manuscript.

David Davis, MD, CCFP, FCFP, Senior Director, AAMC and Brian Wong, MD, FRCPC, AAMC faculty for their guidance in initially delivering the first-cohort Te4Q program.

Submitted: July 15, 2018 EST, Accepted: May 15, 2018 EST

This is an open-access article distributed under the terms of the Creative Commons Attribution 4.0 International License (CCBY-4.0). View this license's legal deed at http://creativecommons.org/licenses/by/4.0 and legal code at http://creativecommons.org/licenses/by/4.0/legalcode for more information. 


\section{REFERENCES}

1. Gallegos A. Unified accreditation system to streamline graduate medical education. AAMC Reporter. https://www.aamc.org/newsroom/reporter/i une2014/384802/gme.html. Published June 2014.

2. Nasca TJ, Philibert I, Brigham T, Flynn TC. The next GME accreditation system: rationale and benefits. NEJM. 2012;366(11):1051-1056.

3. Accreditation Council for Graduate Medical Education. Clinical Learning Environment Review (CLER) program. http://www.acgme.org/acgmeweb/ta bid/436/ProgramandInstitutionalAccreditation/NextA ccreditationSystem/ClinicalLearningEnvironmentRev iewProgram.aspx.

4. Grady EC, Roise A, Barr D, et al. Defining scholarly activity in graduate medical education. J Grad Med Educ. 2012;4(4):558-561.

5. Ledford CJ, Seehusen DA, Villagran MM, Cafferty LA, Childress MA. Resident scholarship expectations and experiences: sources of uncertainty as barriers to success. J Grad Med Educ. 2013;5(4):564-569.

6. Philibert I, Lieh-Lai M, Miller R, Potts JR 3rd, Brigham T, Nasca TJ. Scholarly activity in the next accreditation system: moving from structure and process to outcomes. J Grad Med Educ. 2013;5(4):714-717.

7. Strasser R, Worley P, Cristobal F, et al. Putting communities in the driver's seat: the realities of community-engaged medical education. Acad Med: J Assn Amer Med Coll. 2016;91(5):612.

8. Patel N, Brennan PJ, Metlay J, Bellini L, Shannon RP, Myers JS. Building the pipeline: the creation of a residency training pathway for future physician leaders in health care quality. Acad Med: J Assn Amer Med Coll. 2015;90(2):185-190.

9. Carek PJ, Dickerson LM, Stanek M, Carter C, Godenick MT, Jebally GC, et al. Education in quality improvement for practice in primary care during residency training and subsequent activities in practice. J Grad Med Educ. 2014;6(1):50-54.

10. Manring MM, Panzo JA, Mayerson JL. A framework for improving resident research participation and scholarly output. J Surg Educ. 2014;71(1):8-13.

11. Alweis R, Wenderoth S, Donato A. Effectiveness of iterative interventions to increase research productivity in one residency program. J Comm Hosp Intern Med Perspect. 2015;5(6):29203.
12. Johnson KM, Fiordellisi W, Kuperman E, Wickersham E, Kuehn C, Kamath C, et al. X + Y = Time for QI: Meaningful engagement of residents in quality improvement during the ambulatory block. $J$ Grad Med Educ. 2018;10(3):316-324.

13. Michigan State University College of Osteopathic Medicine. Statewide Campus System. https://scs.ms u.edu.

14. Association of American Medical Colleges. Teaching for Quality: Program Overview. https://ww w.aamc.org/initiatives/cei/te4q.

15. Institute for Healthcare Improvement. IHI Open School. http://www.ihi.org/education/ihiopenschool/ courses/Pages/default.aspx.

16. Ferguson CC, Lamb G. A scholarly pathway in quality improvement and patient safety. Acad Med: $J$ Assn Amer Med Coll. 2015;90:1358-1362.

17. Rodrigue C, Seoane L, Gala RB, Piazza J, Amedee RG. Developing a practical and sustainable faculty development program with a focus on teaching quality improvement and patient safety. Ochsner J. 2012;12(4):338-343.

18. Daniel DM, Casey DEJr, Levine JL, Kaye ST, Dardik $\mathrm{RB}$, Varkey $\mathrm{P}$, et al. Taking a unified approach to teaching and implementing quality improvements across multiple residency programs: the Atlantic Health experience. Acad Med: J Assn Amer Med Coll. 2009;84(12):1788-1795.

19. Stueven J, Sklar DP, Kaloostian P, et al. A residentled institutional patient safety and quality improvement process. Amer J Med Qual. 2012;27(5):369-376.

20. Wong BM, Goguen J, Shojania KG. Building capacity for quality: A pilot co-learning curriculum in quality improvement for faculty and resident learners. J Grad Med Educ. 2013;5(4):689-693.

21. Miller N, MacNew H, Nester J, Wiggins JB, Shealy $\mathrm{C}$, Senkowski C. Jump starting a quality and performance improvement initiative to meet the updated ACGME guidelines. J Surg Educ. 2013;70(6):758-768.

22. Brightspace, Inc. About Desire to Learn (D2). htt p://brightspace.com/. 
23. U.S. Department of Health \& Human Services. HIPAA Administrative Simplification Regulation Text. https://www.hhs.gov/sites/default/files/hipaa-simplifi cation-201303.pdf. Published March 2013.

24. Corser WD, Church B, Rohrer J, Hortos K. The Statewide Campus System Scholarly Activity Developmental Planning Framework for CommunityBased GME Leaders. Spart Med Res J. 2018;3(1):67-83.

25. Roemer BM, Azevedo T, Blumberg B. Looking at graduate medical education through a different lens: A healthcare system's perspective. Acad Med: J Assn Amer Med Coll. 2015;90(9):1231-1235.

26. Liebhaber A, Draper DA, Cohen GR. Hospital strategies to engage physicians in quality improvement. Center for Studying Health System Change: Issue Brief 127. http://hschange.org/CONTE NT/1087/. Published 2009.

27. Kroker-Bode C, Whicker SA, Pline ER, Morgan T, Gazo J, Rudd M, et al. Piloting a patient safety and quality improvement co-curriculum. J Commun Hosp Intern Med Perspect. 2017;7(6):351-357.

28. Wong BM, Etchells EE, Kuper A, Levinson W, Shojania KG. Teaching quality improvement and patient safety to trainees: A systematic review. Acad Med: J Assn Amer Med Coll. 2015;85(9):1425-1439.
29. Carney PA, Eiff P, Green LA, Carraccio C, Smith DG, Pugno PA, et al. Transforming primary care residency training: A collaborative faculty development initiative among family medicine, internal medicine, and pediatric residencies. Acad Med: J Assn Amer Med Coll. 2015;90(8):1054-1060.

30. Yanamadala M, Hawley J, Sloane R, Bae J, Heflin MT, Buhr GT. Development and assessment of a webbased clinical quality improvement curriculum. J Grad Med Educ. 2014;6(1):147-150.

31. Cooney CM, Redett RJI, Dorafshar AH, Zarrabi B, Lifchez SD. Integrating the NAS Milestones and handheld technology to improve residency training and assessment. J Surg Educ. 2014;71(1):39-42.

32. Skye EP, Wimsatt LA, Master-Hunter TA, Locke AB. Developing online learning modules in a family medicine residency. Fam Medic. 2011;43(3):185-192.

33. Wilper AP, Smith CS, Weppner W. Instituting systems-based practice and practice-based learning and improvement: A curriculum of inquiry. Med Educ Online. 2013;18:21612.

34. Kichler K, Kozol R, Buicko J, Lesnikoski B, Tamariz L, Palacio A. A structured step-by-step program to increase scholarly activity. J Surg Educ. 2014;71(6):e19-21.

35. Penrose LL, Yeomans ER, Praderio C, Prien SD. An incremental approach to improving scholarly activity. J Grad Med Educ. 2012;4(4):496-499. 